\title{
CUIDADO AO PRÉ-NATAL SEGUNDO INDICADORES DO PROGRAMA DE HUMANIZAÇÃO DO PRÉ-NATAL E NASCIMENTO
}

\section{PRENATAL CARE ACCORDING TO INDICATORS OF THE PRENATAL AND BIRTH HUMANIZATION PROGRAM}

\section{CUIDADO AL PRE-NATAL SEGÚN INDICADORES DEL PROGRAMA DE HUMANIZACIÓN DEL PRE-NATAL Y NACIMIENTO \\ Débora Alves da Silva ${ }^{1}$}

Como citar esse artigo: Silva DA. Cuidado ao pré-natal Segundo indicadores do programa de humanização do pré-natal e nascimento. Rev Enferm Atenção Saúde, v. 9, n. 2, 111-, 2020. DOI: 10.18554/reas.v9i2.3076

\section{RESUMO}

Objetivo: Analisar a assistência de enfermagem no pré-natal segundo os indicadores do Programa de Humanização do Pré-Natal e Nascimento. Método: Trata-se de uma revisão integrativa da literatura, desenvolvida através da base de dados Scientific Electronic Library Online, em publicações indexadas no período de 2010 a 2015. Resultados: Notou-se que a assistência de enfermagem no cuidado pré-natal enfrenta uma realidade diferente do preconizado pelo Programa de Humanização no Pré-Natal e Nascimento, envolvendo vários fatores que dificultam essa assistência, entre eles o despreparo dos profissionais, divergências entre médico e enfermeiro, dificuldades na captação precoce da gestante, avaliação do risco gestacional, divergências no registro de fichas importantes para o acompanhamento da gestante, entre outros. Conclusão: O profissional de enfermagem tem papel fundamental no cuidado pré-natal, portanto a capacitação, embasada nos princípios do PHPN, torna-se fundamental para o estabelecimento de uma assistência pré-natal efetiva, humanizada e de qualidade, contribuindo assim para a redução da morbimortalidade materna e perinatal.

Descritores: Cuidado Pré-Natal; Parto Humanizado; Enfermagem; Estratégia Saúde da Família; Enfermagem Obstétrica.

\begin{abstract}
Objective: To analyze the prenatal nursing care according to the indicators of the Prenatal and Birth Humanization Program. Method: This is an integrative review of the literature, developed through the Scientific Electronic Library Online database, in indexed publications from 2010 to 2015. Results: It was noted that nursing care in prenatal care faces to a reality different from that advocated by the Prenatal and Birth Humanization Program, involving several factors that make this assistance difficult, among them the lack of preparation of professionals, differences between doctor and nurse, difficulties in the early capture of the pregnant woman, gestational risk assessment, registration of important records for the monitoring of pregnant women, among others. Conclusion: The nursing professional plays a fundamental role in prenatal care, so the training, based on the principles of PHPN, becomes fundamental for the establishment of effective, humanized and quality prenatal care, thus contributing to the reduction of morbidity and mortality maternal and perinatal.
\end{abstract}

Descriptors: Prenatal Care; Humanized birth; Nursing; Family Health Strategy; Obstetric Nursing.

\footnotetext{
${ }^{1}$ Enfermeira. Especialista em Saúde Pública com Ênfase em Saúde da Família. Especialista em Cuidado Prénatal. Enfermeira da Estratégia de Saúde da Família, Prefeitura Municipal de Uberaba/MG.
} 


\section{RESUMEN}

Objetivo: Analizar la asistencia de enfermería en el prenatal según los indicadores del Programa de Humanización del Pre-Natal y Nacimiento. Método: Se trata de una revisión integrativa de la literatura, desarrollada a través de la base de datos Scientific Electronic Library Online, en publicaciones indexadas en el período de 2010 a 2015. Resultados: Se notó que la asistencia de enfermería en el cuidado prenatal enfrenta una enfermedad que se há convertido en una de las principales causas de la crisis económica mundial, en el marco de la crisis económica mundial. El registro de fichas importantes para el acompañamiento de la gestante, entre otros. Conclusión: El profesional de enfermería tiene un papel fundamental en el cuidado prenatal, por lo que la capacitación, basada en los principios del PHPN, se vuelve fundamental para el establecimiento de una asistencia prenatal efectiva, humanizada y de calidad, contribuyendo así a la reducción de la morbimortalidad materna y perinatal.

Descriptores Cuidado Prenatal; Parto Humanizado; Enfermería; Estrategias para la salud de la familia; Enfermería Obstétrica.

\section{INTRODUÇÃO}

A gestação é considerada um período em que ocorre várias mudanças fisiológicas e emocionais na vida da mulher e familiares, que acabam gerando expectativas, emoções, ansiedades, medos e descobertas. Portanto, a assistência ao prénatal se faz fundamental desde o período da concepção até o início do trabalho de parto, tanto para mulher quanto para o bebê. Realizar um cuidado com qualidade permite identificar alterações, patologias durante a gestação, possibilitando a prevenção ou controle dessas, evitando complicações para a saúde da mãe e do concepto, impactando na diminuição das taxas de morbimortalidade materna e fetal. ${ }^{1}$

Segundo o Ministério da Saúde:

Uma atenção pré-natal e puerperal qualificada e humanizada se dá por meio da incorporação de condutas acolhedoras e sem intervenções desnecessárias; do fácil acesso a serviços de saúde de qualidade, com ações que integrem todos os níveis da atenção: promoção, prevenção $e$ assistência à saúde da gestante e do recém-nascido, desde o atendimento ambulatorial básico ao atendimento hospitalar para alto risco. ${ }^{2}$

O Enfermeiro desempenha um papel fundamental no cuidado ao pré-natal, visto que é um profissional qualificado ao atendimento à mulher, tendo importante papel como educador na saúde da população, além de trabalhar com a humanização durante o atendimento prestado, seja na promoção da saúde ou prevenção de agravos. ${ }^{1}$

No que diz respeito a prestação de um cuidado pré-natal com qualidade, o Ministério da Saúde, por meio da portaria $\mathrm{n}^{\circ}$ 569 de $1^{\circ}$ de Junho de 2000, foi instituído o Programa de Humanização no Pré-Natal e 
Nascimento (PHPN) cujo foco são as necessidades de atenção específica à gestante, ao recém-nascido e a mãe no período pós-parto; tendo como prioridades a redução das altas taxas de morbimortalidade materna, peri e neonatal; adoção de medidas que assegurem a melhoria do acesso, cobertura e melhoria da qualidade no atendimento e acompanhamento do pré-natal, parto, puerpério e período neonatal; e investimentos voltados à gestação de alto risco. Este programa tem como fundamento primordial a humanização da assistência obstétrica neonatal na perspectiva da melhoria do acompanhamento do parto e puerpério. ${ }^{3}$

O PHPN institui princípios básicos para serem seguidos pelas instituições de saúde, a fim de fornecer um cuidado com qualidade e humanizado às gestantes e seus familiares. ${ }^{4}$ Tais princípios enfatizam a realização de, no mínimo, seis consultas de acompanhamento pré-natal, sendo, preferencialmente, uma no primeiro trimestre, duas no segundo e três no terceiro trimestre da gestação; realização de uma consulta no puerpério, até 42 dias após o nascimento; e a realização de exames laboratoriais essenciais para o diagnóstico precoce de doenças que podem acarretar complicações para o desenvolvimento fetal e para a saúde materna, tais como $\mathrm{ABO}-\mathrm{Rh}$,
VDRL, toxoplasmose, glicemia jejum, urina rotina e urocultura, testagem anti$\mathrm{HIV}, \mathrm{Hb} / \mathrm{Ht}$, entre outros; além da aplicação de vacina antitetânica; realização de atividades educativas; classificação de risco gestacional em todas as consultas. Além disso, garantir às gestantes, classificadas como de risco, atendimento ou acesso à unidade de referência para atendimento ambulatorial e/ou hospitalar à gestação de alto risco. ${ }^{5}$

A realização dessas atividades pelos enfermeiros e outros profissionais envolvidos na assistência pré-natal implica em repasses de recursos financeiros aos munícipios que aderem ao PHPN. O acompanhamento dessas ações é realizado via Sistema de Acompanhamento do Programa de Humanização no Pré-Natal e Nascimento (SISPRENATAL), este desenvolvido para o registro das atividades realizadas, para o acompanhamento adequado das gestantes inseridas no programa. ${ }^{6}$ Segundo o Ministério da Saúde, esse sistema promove:

“(...) Ações de Promoção, Prevenção e Assistência à Saúde de Gestantes e Recém-Nascidos, ampliando esforços no sentido de reduzir as altas taxas de morbi-mortalidade materna, perinatal e neonatal, melhorando o acesso, da cobertura e qualidade do acompanhamento pré-natal, da assistência ao parto e puerpério e da assistência neo-natal, subsidiando Municípios, Estados e o Ministério da Saúde com 
informações fundamentais para o planejamento, acompanhamento e avaliação das ações desenvolvidas, através do Programa de Humanização no Pré-Natal e Nascimento."7

Partindo-se disso, o presente estudo buscou como objetivo analisar a assistência de enfermagem no pré-natal segundo os indicadores do Programa de Humanização do Pré-Natal e Nascimento; tendo a seguinte questão norteadora: Qual é a realidade da assistência de enfermagem segundo os indicadores do Programa de Humanização do Pré-Natal e Nascimento?

\section{MÉTODO}

Trata-se de uma revisão integrativa da literatura, proveniente de trabalho de conclusão de curso do curso de pós graduação em Cuidado ao Pré-Natal, da Universidade Federal de São Paulo. A revisão foi desenvolvida com base em material já elaborado, constituído por artigos científicos. A busca bibliográfica foi realizada por meio dos seguintes descritores: Cuidado Pré-Natal; Parto Humanizado; Enfermagem; Estratégia Saúde da Família, e Enfermagem Obstétrica, na base de dados Scientific Electronic Library Online (SciELO) e sites oficiais governamentais brasileiro, pois, os mesmos contemplam artigos relevantes e mais direcionados ao objetivo proposto do estudo. Foram selecionados apenas os artigos gratuitamente disponíveis na integra. Estabeleceram-se como critérios de inclusão: publicações em português, pois buscou-se retratar a realidade brasileira visto que o PHPN é um programa nacional; artigos na íntegra que retratassem a temática Assistência Pré-natal e Enfermagem, e publicações indexadas no período de 2010 a 2015. Foram excluídos publicações em outros idiomas, monografias, teses e dissertações, artigos que após a leitura dos resumos não contemplavam à temática do estudo; os que não retratavam, de maneira geral, sobre a realidade brasileira, mas, realidade em cidades específicas no país; os que se repetiam nas bases de dados e os que não estavam disponíveis gratuitamente. $\mathrm{O}$ cruzamento foi realizado através operador booleano “ $A N D$ ”, conforme apresentado no Quadro 1. Assim, com base nos descritores, foram encontrados 291 artigos sendo que após aplicar os critérios de elegibilidade foram selecionados 102 artigos e, onde destes foram utilizados 6 artigos e 4 bases governamentais, totalizando 10 referências, que melhor respondiam à questão de pesquisa. 
Quadro 1: Processo de seleção dos artigos após leitura integral do estudo na base de dados Scientific Electronic Library Online (SciELO), 2018.

\begin{tabular}{|l|c|c|c|}
\hline \multicolumn{1}{|c|}{ Descritor } & Artigos encontrados & Artigos selecionados & Artigos utilizados \\
\hline $\begin{array}{l}\text { Cuidado Pré-Natal } \\
\text { AND Enfermagem }\end{array}$ & 131 & 46 & 1 \\
\hline $\begin{array}{l}\text { Parto Humanizado } \\
\text { AND Cuidado Pré- } \\
\text { Natal }\end{array}$ & 19 & 11 & 1 \\
\hline $\begin{array}{l}\text { Cuidado Pré-natal } \\
\text { AND Estratégia } \\
\text { Saúde da Família }\end{array}$ & 29 & & 1 \\
\hline $\begin{array}{l}\text { Cuidado Pré-Natal } \\
\text { AND Enfermagem }\end{array}$ & & 10 & \\
Obstétrica & 112 & 35 & 3 \\
\hline
\end{tabular}

\section{RESULTADOS}

Os artigos encontrados que compõe a amostra dos estudos são os demonstrados no quadro abaixo.

Quadro 2 - Descrição dos artigos localizados na base de dados Scientific Electronic Library Online (SciELO), em 2018.

\begin{tabular}{|c|c|c|c|c|}
\hline Título do Artigo & $\begin{array}{l}\text { Autores / Ano } \\
\text { de publicação }\end{array}$ & Tipo de Estudo & Resultados & Recomendações / Conclusões \\
\hline $\begin{array}{l}\text { 1. Cuidado pré- } \\
\text { natal e cultura: } \\
\text { uma interface na } \\
\text { atuação da } \\
\text { enfermagem }{ }^{7} \text {. }\end{array}$ & $\begin{array}{l}\text { Alves CN, } \\
\text { Wilhelm LA, } \\
\text { Barreto CN, } \\
\text { Santos CC, } \\
\text { Meincke, } \\
\text { SMK, } \\
\text { Ressel LB } \\
(2015)\end{array}$ & Etnoenfermagem & $\begin{array}{l}\text { Cuidado pré-natal mais } \\
\text { centrado em condutas } \\
\text { tecnicista focadas na } \\
\text { questão biológica da } \\
\text { gestação., carecendo } \\
\text { de valorizar os } \\
\text { costumes, } \\
\text { conhecimentos, } \\
\text { crenças, valores e } \\
\text { praticas de cuidado da } \\
\text { gestante e familiares. }\end{array}$ & $\begin{array}{l}\text { Conhecer o contexto } \\
\text { sociocultural das gestantes para } \\
\text { um cuidado integral da mesma. } \\
\text { Realizar o acolhimento, de } \\
\text { maneira respeitosa, com } \\
\text { diálogo, para o estabelecimento } \\
\text { de um cuidado de qualidade. }\end{array}$ \\
\hline $\begin{array}{l}2 . \text { O Sistema } \\
\text { Único de Saúde } \\
\text { que dá certo: } \\
\text { ações } \\
\text { humanização no } \\
\text { pré-natal } \\
\text {. }\end{array}$ & $\begin{array}{l}\text { Barreto CN, } \\
\text { Wilhelm LA, } \\
\text { Silva SC, } \\
\text { Alves CN, } \\
\text { Cremonese L, } \\
\text { Ressel LB } \\
(2010)\end{array}$ & $\begin{array}{l}\text { Estudo de campo, } \\
\text { descritivo } \\
\text { exploratório de } \\
\text { abordagem } \\
\text { qualitativa. }\end{array}$ & $\begin{array}{l}\text { Cuidado voltado para } \\
\text { os procedimentos } \\
\text { técnicos e rotinas, } \\
\text { deixando de lado o } \\
\text { conhecimento } \\
\text { sociocultural da } \\
\text { mulher. }\end{array}$ & $\begin{array}{l}\text { De acordo com o Programa de } \\
\text { Humanização do Pré-Natal e } \\
\text { Nascimento (PHPN) é } \\
\text { importante reconhecimento do } \\
\text { contexto sociais, acolhendo-a de } \\
\text { maneira respeitosa, assim, } \\
\text { valorizando-as e construindo } \\
\text { confiança e vínculos. Essas } \\
\text { condutas impactam diretamente }\end{array}$ \\
\hline
\end{tabular}




\begin{tabular}{|c|c|c|c|c|}
\hline & & & 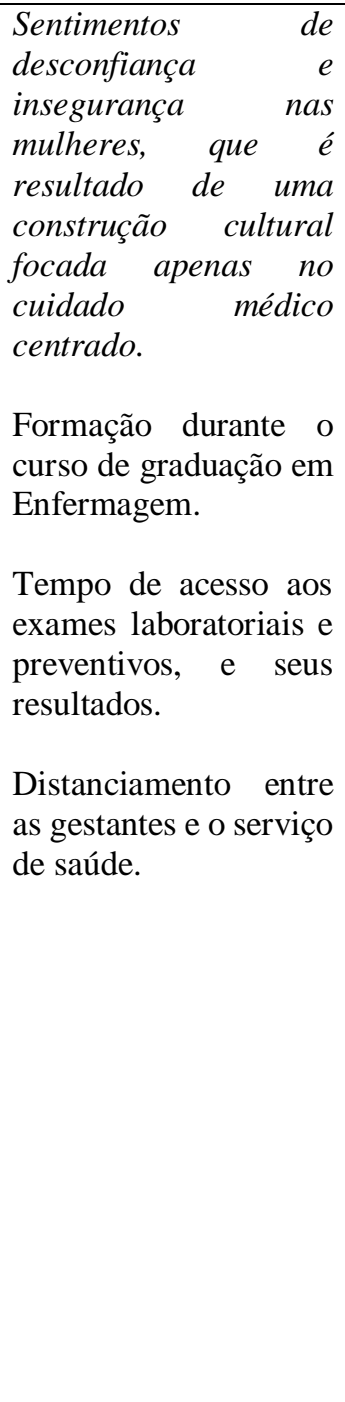 & $\begin{array}{l}\text { na positiva adesão da mulher ao } \\
\text { pré-natal. } \\
\text { A capacitação do Agente } \\
\text { comunitário de saúde para que o } \\
\text { mesmo possa atuar a fim de } \\
\text { ajudar no aumento da cobertura } \\
\text { das ações de pré-natal, também } \\
\text { é fundamental. } \\
\text { Estabelecer medidas para que o } \\
\text { resultados dos exames ocorra } \\
\text { em tempo hábil, facilitando } \\
\text { assim o atendimento e } \\
\text { acompanhamento das gestantes, } \\
\text { além da manutenção do vinculo } \\
\text { da mesma com a } \\
\text { equipe/unidade. } \\
\text { Aprimoramento profissional na } \\
\text { qualidade da atenção prestada } \\
\text { às gestantes, sendo necessário } \\
\text { mudanças no processo } \\
\text { educativo das profissões, } \\
\text { focando também na } \\
\text { aprendizagem proativa, no } \\
\text { reconhecimento do outro e na } \\
\text { escuta ativa das gestantes. } \\
\text { Realizar educação em saúde } \\
\text { com as gestantes, com o intuito } \\
\text { de criar um espaço para a troca } \\
\text { de experiências das mesmas, } \\
\text { tornando-as protagonistas/ } \\
\text { sujeito ativo do cuidado. }\end{array}$ \\
\hline $\begin{array}{l}\text { 3. Avaliação da } \\
\text { assistência pré- } \\
\text { natal em unidade } \\
\text { com estratégia } \\
\text { saúde da } \\
\text { família }{ }^{4} \text { da }\end{array}$ & $\begin{array}{l}\text { Correa MDC, } \\
\text { Tsunechiro } \\
\text { MA, } \\
\text { Lima MOP, } \\
\text { Bonadio IC } \\
(2014)\end{array}$ & Estudo transversal & 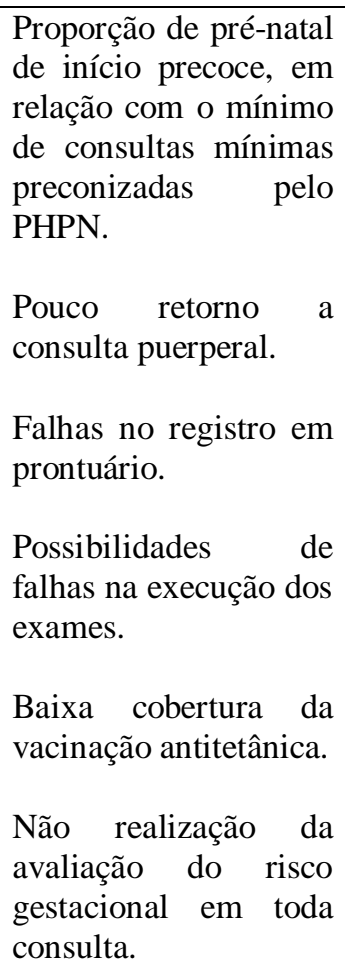 & $\begin{array}{l}\text { Elaborar ações para uma melhor } \\
\text { captação e adesão das gestantes } \\
\text { ao acompanhamento no pré- } \\
\text { natal. } \\
\text { Melhor atenção da equipe às } \\
\text { mulheres que não realizaram } \\
\text { consulta puerperal, visto que } \\
\text { esta reflete na melhoria dos } \\
\text { indicadores de morbidade e } \\
\text { mortalidade materna e perinatal. } \\
\text { Realizar os exames durante a } \\
\text { gestação é fundamental, pois os } \\
\text { mesmos fornecem informações } \\
\text { sobre o estado geral de saúde } \\
\text { da gestante; também sendo } \\
\text { importantes na identificação de } \\
\text { doenças que podem ter } \\
\text { consequências negativas para a } \\
\text { gestante e o concepto. Portanto, } \\
\text { melhorar a gestão na solicitação } \\
\text { e liberação dos resultados de }\end{array}$ \\
\hline
\end{tabular}




\begin{tabular}{|c|c|c|c|c|}
\hline & & & & $\begin{array}{l}\text { exames solicitados é } \\
\text { fundamental. } \\
\text { O profissional não deve perder a } \\
\text { oportunidade para a atualização } \\
\text { do esquema vacinal da gestante, } \\
\text { visto que a mesma procura } \\
\text { frequentemente o serviço de } \\
\text { saúde para o acompanhamento } \\
\text { do pré-natal. } \\
\text { Realizar e fazer o registro os } \\
\text { procedimentos realizados, além } \\
\text { de avaliar o risco gestacional em } \\
\text { todas as consultas; essas } \\
\text { condutas estão entre as } \\
\text { condições básicas para um } \\
\text { cuidado pré-natal efetivo. }\end{array}$ \\
\hline 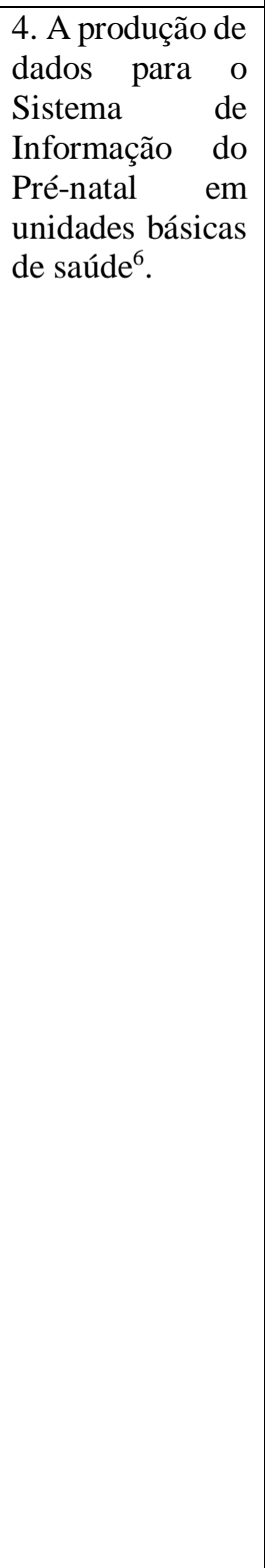 & $\begin{array}{l}\text { Lima AP, } \\
\text { Correa ACP } \\
(2013)\end{array}$ & $\begin{array}{l}\text { Estudo qualitativo, } \\
\text { exploratório e } \\
\text { descritivo. }\end{array}$ & 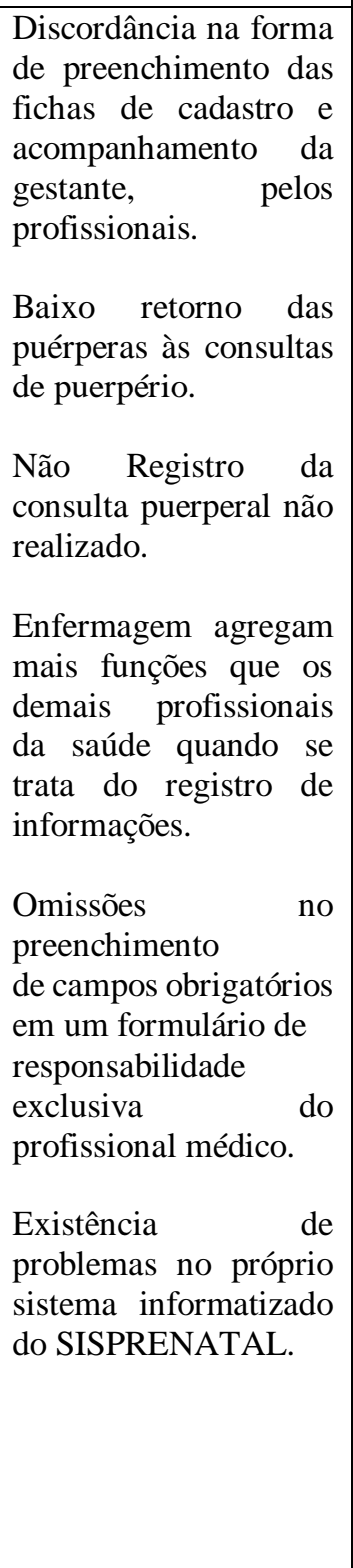 & $\begin{array}{l}\text { Campos negligenciados pelos } \\
\text { profissionais, durante o } \\
\text { preenchimento das fichas. } \\
\text { Infelizmente, há gestantes que } \\
\text { chegam a realizar consultas de } \\
\text { pré-natal sem o cadastramento } \\
\text { no SISPRENATAL. } \\
\text { Preenchimento da ficha de } \\
\text { cadastro da gestante sendo } \\
\text { realizado predominantemente } \\
\text { pelos enfermeiros, ou muitas } \\
\text { vezes por outros profissionais } \\
\text { que não podem realizar tal } \\
\text { registro. } \\
\text { Gestantes que esquecem a data } \\
\text { da ultima menstruação ou não } \\
\text { comparecem ao serviço de } \\
\text { saúde com a documentação } \\
\text { solicitada, implica no } \\
\text { cadastramento da mesma. } \\
\text { Capacitar e conscientizar os } \\
\text { profissionais quanto à } \\
\text { importância do registro nas } \\
\text { fichas, de maneira correta, para } \\
\text { a produção de dados no } \\
\text { SISPRENATAL; pois trata-se } \\
\text { de uma fonte geradora } \\
\text { importante de } \\
\text { dados fundamentais para o } \\
\text { planejamento e a avaliação da } \\
\text { assistência pré-natal e repasse } \\
\text { de recursos. } \\
\text { Conscientização da população } \\
\text { quanto à importância da } \\
\text { consulta puerperal. }\end{array}$ \\
\hline
\end{tabular}




\begin{tabular}{|c|c|c|c|c|}
\hline & & & & $\begin{array}{l}\text { Realizar manutenção do sistema } \\
\text { para a produção de informações } \\
\text { adequadas com a realidade do } \\
\text { município. }\end{array}$ \\
\hline $\begin{array}{l}\text { 5. Análise do } \\
\text { exercício de } \\
\text { competências } \\
\text { dos não médicos } \\
\text { para atenção à } \\
\text { Maternidade?. }\end{array}$ & $\begin{array}{l}\text { Narchi } \\
(2010)\end{array}$ & $\begin{array}{l}\text { Estudo descritivo } \\
\text { e exploratório }\end{array}$ & $\begin{array}{l}\text { Formação } \quad \text { de } \\
\text { profissionais } \\
\text { enfermeiros com } \\
\text { pouca experiência em } \\
\text { obstetrícia. }\end{array}$ & $\begin{array}{l}\text { "Necessidade de educação } \\
\text { permanente dos profissionais } \\
\text { para que sejam capazes de } \\
\text { prestar assistência humanizada e } \\
\text { solidamente alicerçada pela } \\
\text { competência em obstetrícia, o } \\
\text { que exige conhecimentos e } \\
\text { habilidades específicos, tanto da } \\
\text { fisiopatologia obstétrica quanto } \\
\text { dos aspectos socioculturais } \\
\text { dessa fase da vida da mulher, } \\
\text { nem sempre contemplados pelos } \\
\text { cursos de graduação em } \\
\text { Enfermagem, cujo foco no } \\
\text { Brasil ainda é a atenção } \\
\text { hospitalar e a administração dos } \\
\text { serviços" (p. 153). }\end{array}$ \\
\hline $\begin{array}{l}\text { 6. Protocolo na } \\
\text { assistência pré- } \\
\text { natal: ações, } \\
\text { facilidades } \\
\text { dificuldades dos } \\
\text { enfermeiros da } \\
\text { Estratégia } \\
\text { Saúde } \\
\text { Família }^{1} \text { de } \\
\end{array}$ & $\begin{array}{l}\text { Rodrigues EM, } \\
\text { Nascimento } \\
\text { RG, } \\
\text { Araujo A } \\
\text { (2011) }\end{array}$ & Estudo qualitativo & 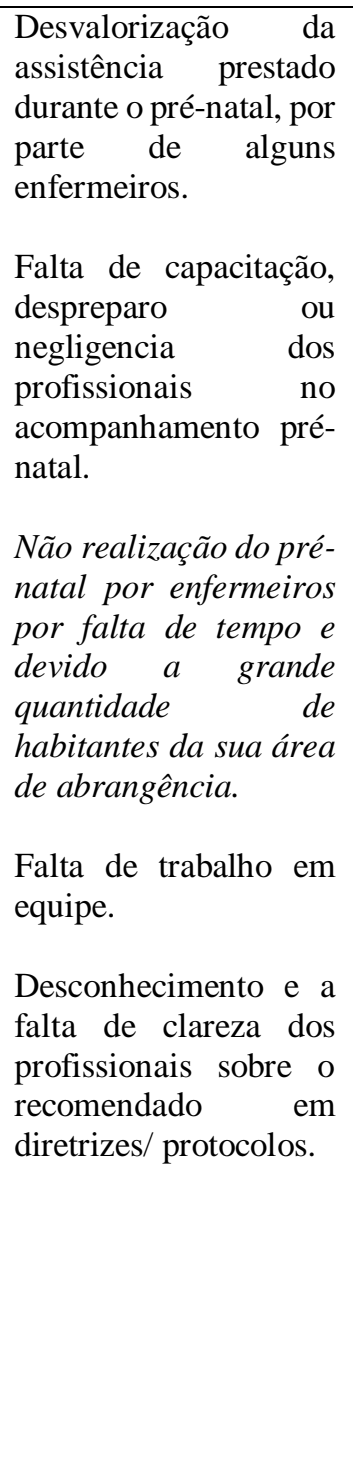 & $\begin{array}{l}\text { "A assistência pré-natal não se } \\
\text { limita apenas aos procedimentos } \\
\text { realizados dentro do consultório } \\
\text { médico. De acordo com o } \\
\text { Manual Técnico de Assistência } \\
\text { Pré-Natal do Ministério da } \\
\text { Saúde, uma atenção pré-natal de } \\
\text { boa qualidade inclui tanto ações } \\
\text { simples (orientações, grupos de } \\
\text { gestantes, solicitação de exames } \\
\text { para diagnóstico, visitas } \\
\text { domiciliares, entre outros) } \\
\text { quanto procedimentos } \\
\text { realizados na consulta de pré- } \\
\text { natal de risco habitual pelo } \\
\text { médico ou pelo enfermeiro" (p. } \\
\text { 1045). } \\
\text { Capacitação e preparo dos } \\
\text { profissionais, para abtenção de } \\
\text { competências práticas } \\
\text { habilidades para a resolução de } \\
\text { problemas, pensamento crítico e } \\
\text { a tomada de decisões, assim, } \\
\text { implicando em uma assistência } \\
\text { ao pré-natal qualificada. } \\
\text { Planejar a assistência do } \\
\text { enfermeiro, para que o cuidado } \\
\text { pré-natal possa ser realizado } \\
\text { pelo mesmo sem que seja } \\
\text { prejudicado o serviço da } \\
\text { unidade. } \\
\text { A equipe da unidade necessita } \\
\text { desempenhar um trabalho em } \\
\text { conjunto, para que a assistência }\end{array}$ \\
\hline
\end{tabular}




\begin{tabular}{|l|l|l|l|}
\hline & & $\begin{array}{l}\text { seja oferecida de maneira } \\
\text { integral ao usuário, conforme } \\
\text { preconizado. }\end{array}$ \\
$\begin{array}{l}\text { Uso de protocolos de atribuições } \\
\text { do enfermeiro na assistência } \\
\text { pré-natal. }\end{array}$ \\
\hline
\end{tabular}

\section{DISCUSSÃO}

Cinco estudos foram realizados em unidades básicas de saúde $(\mathrm{UBS})^{1,4,6-9}$, e apenas um estudo foi realizado em UBS e hospitais com leitos obstétricos exclusivamente destinados ao SUS. ${ }^{10}$ Dentre esses, dois foram estudos quantitativos realizados no estado de $\mathrm{SP}^{4,9}$, sendo um de natureza descritiva exploratória ${ }^{10}$, e o outro estudo transversal. ${ }^{4}$ Os outros quatros artigos ambos são estudos

- Condutas tecnicistas focadas na questão biológica da gestação $0^{8,9}$

- Desvalorização das crenças prévias das gestantes ${ }^{8}$

- Processo de formação dos enfermeiros na graduação 9,10

- Tempo de espera para o resultado dos exames realizados ${ }^{9}$

- Proporção de pré-natal com início precoce $^{4}$

- Pouco retorno à consulta puerperal ${ }^{4,6}$

- Falhas nos registros na ficha de cadastro e acompanhamento ${ }^{4,6}$ qualitativos $^{1,6-9}$, sendo três desses de natureza descritiva e exploratória ${ }^{1,6}$, e um de etnoenfermagem. ${ }^{8}$

Após a análise dos seis artigos selecionados, nota-se que a assistência de enfermagem no cuidado pré-natal muitas vezes enfrenta uma realidade diferente do preconizado pelo PHPN. Dentre vários pontos que mais dificultam essa assistência, destacam-se os seguintes:

- Baixa cobertura da vacinação antitetânica $^{4}$

- não realização do risco gestacional em todas as consultas 4

- Falta de capacitação, despreparo ou negligência dos profissionais no acompanhamento pré-natal ${ }^{1}$

- Sobrecarga de trabalho para o enfermeiro $^{1}$

- Falta de trabalho em equipe, e o desconhecimento e a falta de clareza dos profissionais sobre o recomendado em diretrizes/ protocolos preconizados $^{1}$ 
Um dos principais princípios enfatizados pelo PHPN é o acolhimento e atendimento humanizado e com qualidade. Pode-se observar que muitas vezes o enfermeiro não valoriza o saber/conhecimento prévio, práticas e crenças das gestantes. ${ }^{8} \mathrm{Um}$ fator que favorece essa desvalorização é o próprio processo de formação na graduação de Enfermagem, onde o saber está voltado basicamente para as questões biológicas, deixando de lado uma aprendizagem proativa, no reconhecimento do outro e na escuta ativa das gestantes. ${ }^{9}$

Saber respeitar o momento de cada gestação, acolher a mulher de maneira respeitosa, com diálogo, troca de experiências, conhecendo o contexto sociocultural da mulher é fundamental para um cuidado integral da mesma. ${ }^{8} \mathrm{O}$ enfermeiro, com seu papel de educador, deve realizar educação em saúde com as gestantes, com o intuito de criar um espaço para a troca de experiências das mesmas, tornando-as protagonistas/ sujeito ativo do cuidado. ${ }^{9}$ Essas atitudes são importantes para o estabelecimento de vínculo $\mathrm{e}$ confiança entre o enfermeiro e a gestante, assim, implicando em um cuidado com qualidade e melhor adesão da mulher ao pré-natal. $^{8,9}$
Destaca-se também na literatura os exames laboratoriais e preventivos que são realizados durante o pré-natal, e o tempo de acesso aos resultados. ${ }^{9}$ Esse fator está ligado diretamente à adesão da gestante ao pré-natal. ${ }^{9}$ Portanto, elaborar estratégias para a realização dos exames e acesso aos resultados em tempo hábil contribui para a resolutividade das ações, além de melhorar a aproximação da gestante com a unidade de saúde. ${ }^{9}$

Outro aspecto importante abordado foi a proporção de pré-natal de início precoce, em relação com o mínimo de consultas mínimas preconizadas pelo PHPN, e o retorno das mulheres à consulta puerperal. $^{4,6}$ Infelizmente, ainda nota-se dificuldade com a captação precoce das gestantes para o início do pré-natal e a adesão das mesmas, além do baixo número de retornos à consulta puerperal. ${ }^{4,6}$ É importante enfatizar que 0 acompanhamento pré-natal e puerpério devem ser realizados de maneira integral, humanizada e resolutiva pela equipe responsável pela sua área de abrangência, mesmo quando as mulheres estão em acompanhamento seja no particular ou em outra unidade. Uma estratégia é a capacitação do Agente comunitário de saúde a fim de ajudar no aumento da 


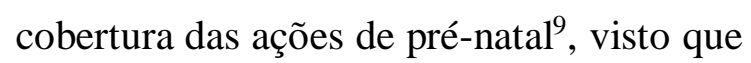
este profissional esta em contato direto com a família e o serviço de saúde. Pode-se trabalhar com a capacitação dos profissionais de enfermagem para que seja melhorada a atenção da equipe às mulheres que não realizaram consulta puerperal ${ }^{4}$, além de realizar ações para melhor conscientização da população quanto à importância desta consulta ${ }^{6}$; visto que esta reflete na melhoria dos indicadores de morbidade e mortalidade materna e perinatal. $^{4}$

Outros dois princípios enfatizados pelo PHPN são a aplicação da vacina antitetânica e a realização da avaliação do risco gestacional em toda consulta. ${ }^{5}$ Entretanto, estudos mostram que ainda há uma baixa adesão/ cobertura dessa imunização nas gestantes. ${ }^{4}$ Portanto, o enfermeiro não deve perder a oportunidade, durante as visitas da gestante à unidade para o pré-natal, para enfatizar a importância da vacinação e estimular a realização da mesma, visto que a não imunização da mulher pode acarretar em consequências para a saúde dela e de seu concepto. No que diz respeito a avaliação e registro do risco gestacional em toda consulta, um estudo mostrou que muitas vezes há divergências entre o profissional médico e enfermeiro, que algumas vezes não preenchem as fichas corretamente. ${ }^{6} \mathrm{O}$ estudou mostrou que quando o médico não anota o risco gestacional da gestante o enfermeiro procura indícios no prontuário e classifica essa mulher. ${ }^{6}$ Entretanto, já ocorreu desta classificação acontecer de maneira errada. ${ }^{6}$ Portanto, capacitar e conscientizar os profissionais de enfermagem quanto à importância do registro nas fichas, de maneira correta, é fundamental para um cuidado pré-natal efetivo e de qualidade. ${ }^{6}$

Outro problema apontado nos artigos foi a maneira como é realizado o registro nas fichas de cadastro e acompanhamento da gestante que são repassadas para o SISPRENATAL, sistema onde se faz o acompanhamento das gestantes inseridas no PHPN. ${ }^{6}$ A produção de dados é essencial para o repasse de recursos financeiros para as instituições, conforme abordado anteriormente neste estudo. Nota-se divergências no momento do preenchimento pelos enfermeiros e médicos, onde é feito de forma parcial sendo alguns campos importantes negligenciados. ${ }^{6}$ Algumas vezes a gestante também contribui para o preenchimento inadequado, quando não lembra a da data da última menstruação (DUM) ou esquece de levar as documentações importantes para completar as informações solicitadas nas fichas. ${ }^{6}$ O estudou aponta também que muitas vezes essa função de preenchimento de fichas é delegada apenas ao profissional 
enfermeiro, sendo que o profissional que realizou a consulta é o responsável por tal ação. ${ }^{6}$ Portanto, a capacitação dos profissionais envolvidos no cuidado prénatal, seja o médico ou o enfermeiro, é importante para que seja realizado o registro de maneira padronizada, conforme preconizado pelo PHPN, assim, não interferindo nos recursos repassados e no cuidado prestado à gestante.

Destaca-se também a desvalorização pelo próprio profissional de enfermagem quanto ao cuidado prestado durante o pré-natal pelo mesmo, atribuindo que esta função deve ser realizada apenas pelo médico. ${ }^{1} \mathrm{O}$ enfermeiro deve estar ciente que a assistência prestada à gestante não se limita apenas aos procedimentos realizados dentro do consultório médico, mas sim a um cuidado que envolve também a parte educativa, como as orientações, grupos de gestantes, visitas domiciliares, entre outros; onde estes podem ser realizados tanto pelo médico ou pelo Enfermeiro. ${ }^{1}$ Portanto, o enfermeiro deve se valorizar e compreender que ele tem preparo suficiente para executar tal função. E que caso este não tenha segurança para a realização da mesma, o profissional deve buscar capacitação apropriada e o planejamento da assistência, a fim de obter competências práticas e habilidades para a resolução de problemas, pensamento crítico e a tomada de decisões, assim, implicando em uma assistência ao pré-natal qualificada. $^{1}$

\section{CONCLUSÃO}

Os resultados deste estudo indicam que a realidade vivenciada pelos profissionais de enfermagem ainda se difere do preconizado pelo PHPN. O despreparo do profissional, divergências entre $o$ profissional médico e enfermeiro, dificuldades na captação precoce da gestante, dificuldades no acesso aos resultados do exames laboratoriais, avaliação do risco gestacional, dificuldade na captação das puérperas para o retorno à consulta puerperal e as divergências no registro de fichas importantes para $o$ acompanhamento da gestante; foram os principais fatores que dificultaram a prática desses profissionais, conforme estabelecido pelo PHPN.

O profissional de enfermagem tem papel fundamental no cuidado pré-natal, portanto a capacitação, embasada nos princípios do PHPN, torna-se fundamental para o estabelecimento de uma assistência pré-natal efetiva, humanizada e de qualidade, contribuindo assim para a redução da morbimortalidade materna e perinatal.

Dentre as limitações do estudo, nota-se que há poucos artigos relacionados 
à questão de pesquisa, principalmente estudos voltados para todo o território brasileiro; portanto, novos estudos são necessários para se entender melhor essas dificuldades vivenciadas pelos profissionais de saúde, em cada região do país; assim, englobando toda a realidade brasileira, e não apenas a realidade de algumas cidades especificas.

\section{REFERÊNCIAS}

1. Rodrigues EM, Nascimento RG, Araujo A. Protocolo na assistência pré-natal: ações, facilidades e dificuldades dos enfermeiros da Estratégia de Saúde da Família. Rev Esc Enferm USP. [Internet]. 2011 [citado em 08 dez 2017]; 45(5):1041-47. Disponível em:

https://www.scielo.br/pdf/reeusp/v45n5/v4 5n5a02.pdf

2. Ministério da Saúde (Brasil), Secretaria de Atenção à Saúde. Pré-natal e puerpério: atenção qualificada e humanizada: manual técnico [Internet]. Brasília, DF: Ministério da Saúde; 2006 [citado em 25 mar 2018]. Disponível em:

http://bvsms.saude.gov.br/bvs/publicacoes/ manual_pre_natal_puerperio_3ed.pdf

3. Ministério da Saúde (Brasil), Secretaria Executiva. Programa de Humanização do Parto. Humanização no pré-natal e nascimento. Brasília, DF: Ministério da Saúde; 2002.

4. Correa MDC, Tsunechiro MA, Lima MOP, Bonadio IC. Avaliação da assistência prénatal em unidade com estratégia saúde da família. Rev Esc Enferm USP. [Internet]. 2014 [citado em 08 dez 2017]; 48(Esp):2432. Disponível em: https://www.scielo.br/pdf/reeusp/v48nspe/ pt_0080-6234-reeusp-48-esp-024.pdf

5. Ministério da Saúde (Brasil). Portaria $n^{\circ}$ 569 , de $1^{\circ}$ de junho de 2000. Institui o
Programa de Humanização no Pré-Natal e Nascimento [Internet]. Brasília, DF:

Ministério da Saúde; 2000 [citado em 25 mar 2018]. Disponível em: http://bvsms.saude.gov.br/bvs/saudelegis/g m/2000/prt0569_01_06_2000_rep.html

6. Lima AP, Correa ACP. A produção de dados para o Sistema de Informação do Pré-Natal em unidades básicas de saúde. Rev Esc Enferm USP. [Internet]. 2013 [citado em 08 dez 2017]; 47(4):876-83. Disponível em:

https://www.scielo.br/pdf/reeusp/v47n4/00 80-6234-reeusp-47-4-0876.pdf

7. Ministério da Saúde (Brasil). SisPreNatal [Internet]. Brasília, DF: Ministério da Saúde; [2008] [citado em 25 dez 2018]. Disponível em: http://www2.datasus.gov.br/DATASUS/in dex.php?area $=060305$

8. Alves CN, Wilhelm LA, Barreto CN, Santos CC, Meincke SMK, Ressel LB. Cuidado pré-natal e cultura: uma interface na atuação da enfermagem. Esc Anna Nery Rev Enferm. [Internet]. 2015 [citado em 08 dez 2017]; 19(2):265-71. Disponível em: https://www.scielo.br/pdf/ean/v19n2/14148145-ean-19-02-0265.pdf

9. Barreto CN, Wilhelm LA, Silva SC, Alves CN, Cremonese L, Ressel LB. O Sistema Único de Saúde que dá certo: ações de humanização no pré-natal. Rev Gauch Enferm. [Internet]. 2015 [citado em $08 \mathrm{dez}$ 2017]; 36(n Esp):168-76. Disponível em: https://www.sicelo.br/scielo.php?pid=S198 3-

$14472015000500168 \&$ script $=$ sci_abstract \&tlng $=\mathrm{pt}$

10 Narchi NZ. Analise do exercício de competências dos não médicos para atenção à Maternidade. Saúde Soc. [Internet]. 2010 [citado em 08 dez 2020]; 19(1):147-58. Disponível em: https://www.scielo.br/pdf/sausoc/v19n1/12 .pdf

RECEBIDO: $21 / 07 / 2018$

APROVADO: 03/06/2019

PUBLICADO: $12 / 2020$ 